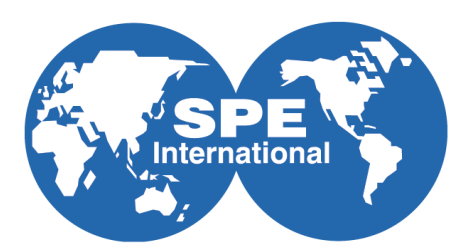

\title{
SPE 187068-MS
}

\section{Knudsen-Like Scaling May Be Inappropriate for Gas Shales}

Tadeusz W. Patzek

\author{
Ali I. Al-Naimi Petroleum Engineering Research Center (ANPERC), Physical Sciences and Engineering Division \\ King Abdullah University of Science and Technology (KAUST) Thuwal, Kingdom of Saudi Arabia 23955-6900 \\ E-mail address: tadeusz.patzek@kaust.edu.sa
}

Copyright 2017, Society of Petroleum Engineers

This paper was prepared for presentation at the Annual Technical Conference and Exhibition held in San Antonio, Texas, U.S.A., 9-11 October 2017

This paper was selected for presentation by an SPE program committee following review of information contained in an abstract submitted by the author(s). Contents of the paper have not been reviewed by the Society of Petroleum Engineers and are subject to correction by the author(s). The material does not necessarily reflect any position of the Society of Petroleum Engineers, its officers, or members. Electronic reproduction, distribution, or storage of any part of this paper without the written consent of the Society of Petroleum Engineers is prohibited. Permission to reproduce in print is restricted to an abstract of not more than 300 words; illustrations may not be copied. The abstract must contain conspicuous acknowledgment of SPE copyright.

\section{Summary}

We assert that a classification of gas flow regimes in shales that is widely accepted in the petroleum industry, may be inconsistent with the physics of high-pressure gas flow in capillaries. This classification follows from the 1946 work by Brown et al. (1946) that deals with the flow of gases in large industrial metal pipes, elbows and orifices under vacuum, with gas pressures of the order of $1 \mathrm{~mm} \mathrm{Hg}$ or less. In another pioneering paper that year, Tsien (1946) analyzed the hypersonic flight of rockets in the thermosphere (above 50 miles of altitude), and established the widely accepted Knudsen flow regimes for the high-Reynolds, high-Mach flow of rarified gases. We show why both these papers are not quite applicable to flow of compressed gas in the hot, high-pressure shale pores with rough surfaces. In addition, it may be inappropriate to use the capillary tube metaphor to describe shale micropores or microcracks, simply because each is fed with gas by dozens or hundreds of intricately connected nanopores, which themselves may be slits rather than circular cylinders, and are charged with the dense, liquid-like gas.

In the small-scale, low-velocity flows of gases, failure of the standard Navier-Stokes description (the standard Darcy law in petroleum engineering) can be quantified by the Knudsen number, ratio of the mean free path, $\lambda$, of gas molecules at the reservoir pressure and temperature to the characteristic pore radius, $R$. We carefully enumerate the multiple restrictive conditions that must hold for the slip-flow boundary condition to emerge. We also describe the dependence of the slip correction factor on the gas pressure and temperature, as well as the median pore size and rock roughness. In the derivation, we revisit the original approaches of Helmholtz and von Piotrowski (1860) and Maxwell, Niven (1890), which were somehow lost in the multiple translations from physics to petroleum engineering.

For example, in Barnett mudrocks, naturally occurring pores are predominantly associated with organic matter and pyrite framboids. In organic matter, the median pore length is $100 \mathrm{~nm}$, Loucks et al. (2009), and the pore radii are likely to be between 1 and $10 \mathrm{~nm}$, Clarkson et al. (2013). Other thermally mature mudrocks may be similar, Ross and Bustin (2009), or not, Clarkson et al. (2013). With $R=50 \mathrm{~nm}$, the ratio of $\lambda / R$ is less than 0.1 for pressures exceeding 60 bars. When we compare the actual slip-flow correction with the accepted classification of gas flow regimes, there is an order of magnitude discrepancy. It appears that our new classification is conservative for pores larger than $5 \mathrm{~nm}$ in radius. Therefore, unless the fraction of gas molecules that are bounced off diffusively from the rough pore walls is very low, slip flow is unlikely to dominate in shales. 
The generally accepted "Knudsen-diffusion" in shales is based on a mistranslation of the flow physics and may give theoretically unsound predictions of the increased permeability of shales to gas flow. This increase of permeability is real, and it comes from the micropores, fine-scale microfractures and cracks. The nanopores in shales provide gas storage by sorption and capillary condensation of heavier gas components. In the smallest nanopores even methane molecules are increasingly ordered and resemble more liquid than gas. These nanopores feed the macroscopic flow paths in ways that are not captured well by the generally accepted equations.

KEYWORDS: gas transport, nanopores, micropores, microcracks, permeability enhancement

\section{Introduction}

In his pioneering experiments, Klinkenberg (1941) showed that for gas pressures below 1 bar, gas permeability can substantially exceed that for liquid, see Fig. 1. In a subsequent comment on the Klinkenberg paper, Morris Muskat observed:

As Dr. Klinkenberg points out, the theory of slip in the flow of gases through capillaries has been available for some 65 years $^{1}$. Yet those of us who have been working on permeability measurements for the last 10 years must accept with embarrassment the responsibility for having overlooked the basic applications of this theory to the flow of gases through porous media. Occasional discrepancies between permeability measurements with gases and liquids undoubtedly have been observed by all experimenters. However, it seems that the line of least resistance has been followed heretofore in attributing these discrepancies merely to- experimental errors. It has remained for Dr. Klinkenberg to trace them down and to prove without question that they are an expression of a real physical phenomenon, and to expose in addition the quantitative features of the effect in such a way that it can be controlled and interpreted.

Perhaps the only excuse that can be given for previous failure to recognize the phenomenon of slip is that, if the mean free paths as established by other methods were used and the effective pore radii generally accepted as characterizing reservoir sands were introduced in the theoretical formulas for flow with slip, the correction term would have been a priori predicted as being far too small to play any role in the measurements. Of course, the basic reason for the apparently anomalous importance of the slip is the tremendous surface area in a sand as compared to that in a capillary tube.

Size distribution of a single pore is a distribution of radii of the largest spheres that can be fitted at each point along this pore, Silin and Patzek (2006). "Pore size" or "pore body radius" is the radius of maximum sphere that can be inscribed into a pore, while "pore throat" refers to the radius of minimum inscribed sphere common to two adjacent pores. In slit-like pores, pore throats and bodies are the same, and often pore widths are reported to account for gas sorption. For a thorough discussion of the murky issue of pore sizes, see Silin and Patzek (2006) and several other references cited here.

Note that a common method of establishing pore size distribution through the pressure-controlled mercury injection capillary pressure (MICP) measurements, captures pore throat radii, rather than pore sizes. Thus, MICP almost always understates pore sizes. In compressible mudrocks, and at high mercury injection pressures, MICP also compresses the mudrock skeleton and may be inaccurate, Clarkson et al. (2013). Far more information about pore spaces can be obtained from volume-controlled mercury porosimetry. Yuan and Swanson (1989) and Yuan (1991) demonstrated this in landmark experiments with their apparatus for pore examination (APEX). With APEX, it is possible to resolve the pore space of a rock sample into two interconnected parts. One part identifies individual pore bodies, which are regions of lowered capillarity. The other part corresponds to pore throats that interconnect with pore bodies. Subsequently, Toledo et al. (1994) developed a mechanistic model of pore-level displacement under the quasi-static conditions of APEX. This model can be used to

\footnotetext{
${ }^{1}$ Bolding by TWP. Seventy six years have passed since the publication of Klinkenberg's paper, and today we may be erring on the other side, exaggerating the importance of slip in the flow of gases in the high-pressure, low permeability rocks, in which other transport mechanisms operate.
} 
characterize pore space of a rock and saturation history. When average pore size is measured in tens of nanometers, APEX is extremely difficult to apply.

The pore size distributions from $\mathrm{N}_{2}$ and $\mathrm{CO}_{2}$ desorption are determined by modeling the progressive removal of adsorbate from pore surfaces, Adesida et al. (2011), regardless of whether these surfaces represent pore throats or pore bodies. For slit-like pores, pore throats and bodies are the same. In this case, adsorption and MICP analysis should yield similar results. To add to the confusion, Loucks et al. (2012), for example, measured pore lengths using FIB/SEM, and reported them as pore sizes.

In summary, "pore sizes," whatever this term means to different authors, in the crushed samples of mudrocks are often inferred from small-angle and ultra-small-angle neutron scattering, multistage desorption measurements, and molecular or statistical physics calculations; these sizes are not directly measured.

Since a clear definition of pore sizes is needed, we adopt the following classification:

$$
\text { Pore size (radius) }=\left\{\begin{array}{l}
=0.4 \mathrm{~nm}, \text { size of } \mathrm{CH}_{4} \text { molecule } \\
>0.5 \mathrm{~nm}, \text { but } \leq 1 \mathrm{~nm} \text {, picopore } \\
>1 \mathrm{~nm}, \text { but } \leq 100 \mathrm{~nm}, \text { nanopore } \\
>100 \mathrm{~nm}, \text { but } \leq 10,000 \mathrm{~nm}(10 \mu \mathrm{m}), \text { micropore } \\
>10 \mu \mathrm{m}, \text { but } \leq 10^{6} \mathrm{~nm}(1 \mathrm{~mm}), \text { mesopore }
\end{array}\right.
$$

A decent horizontal well in the Barnett shale, Patzek et al. $(2013,2014)$, might produce in excess of $2 \times 10^{25}$ methane molecules per second for over 2 years, see Fig. 2. Suppose that these molecules are $0.389 \mathrm{~nm}$ in diameter, and are densely packed in the representative, Ross and Bustin (2007), cylindrical pores with average radius ${ }^{2} R=5 \mathrm{~nm}$ and length of $3 R$. Let us assume that the almost perfectly ordered methane density is $80 \%$ of that in hexagonal sphere packing. Then the highest

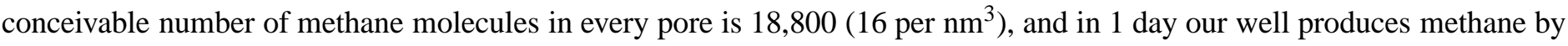
evacuating all molecules from $1,350 \mathrm{~m}^{3}$ of bulk rock, if the porosity is $8 \%$, close to average for all compacted shales at depth, Athy (1930). In three years, if the recovery factor is 0.3 , the methane is produced by volumetric expansion from 5 million $\mathrm{m}^{3}$ of bulk rock. In this example, there is no slip in the dense, almost liquid-like methane, and the 5 (or less) nm pores must be connected over the distances of tens of meters. If formation height is $30 \mathrm{~m}$ and wellbore length is $1 \mathrm{~km}$, width of the bulk rock parallelepiped associated with the well is $165 \mathrm{~m}$. These multiscale estimates are self-consistent. With ten two-sided hydrofractures, one immediately calculates that the molar flux of produced gas is 0.025 mole $\left(\mathrm{s} \mathrm{m}^{2}\right)^{-1}$ or $100-1800$ times less then the molar fluxes used by Roy et al. (2003) in their experiments and calculations. Similarly, the micro-channel outlet gas velocity in the experiments by Roy et al. (2003) was between 0.06 and $1 \mathrm{~m} / \mathrm{s}$, compared with $2 \times 10^{-5} \mathrm{~m} / \mathrm{s}$ for the reservoir flow at fracture face at 34 bars. In summary, the flow experiments by Roy et al. (2003) are not quite applicable to gas flow in a mudrock reservoir and their use by Javadpour (2009) seems to be unwarranted.

The nanopores and micropores in sedimentary, compacted silicious and calcarious mudrocks ("shales") are connected, but have very low permeability. This low permeability results from the small cross-sections of pore throats and the scaledependent connectivity that ranges from strong at nanoscale to increasingly sparser at micro and higher scales. Patzek et al. (2013) and Marder et al. (2015) showed that methane in shales is produced through the highways of loosely connected micropores and multiscale cracks, man-made and natural, into which a background continuum of the tiny nanopores feeds gas. This background continuum with the ordered, densely packed methane molecules can masquerade at times as the BET-like, multi-layer methane adsorption, Yu et al. (2016).

Nanopore densities within grains of organic matter can be high. Grains containing hundreds of nanopores are common;

\footnotetext{
${ }^{2}$ If average pore radius were 1 or $2 \mathrm{~nm}$, our argument would remain the same.
} 
in one case a single 10.8- $\mu \mathrm{m}$-diameter grain contained more than 1,000 nanopores of various shapes and sizes, Loucks et al. (2009), see Fig. 3.

The fractured gas-bearing mudrock formations (shales) are the essentially multiscale, Nelson (2009), and multiphysics systems, Marder et al. (2015), and their behavior is complex. Yet, we try to replace shale complexity with a set of slim cylindrical capillaries that flow methane with slip at the capillary walls.

The remainder of this paper describes a 180 year-long path of classical physics that has led to the models of Knudsen diffusion of gases in capillaries, Brown et al. (1946), and the Knudsen flow regimes in the high Reynolds number flows of rarified gases, Tsien (1946). The latter flow regimes were later transplanted by Javadpour et al. (2007) to petroleum literature. Among the famous scientists and engineers who developed the theories of liquid flow and slip flow of gases in capillaries and pipes, and along planes, were Poiseuille, Hagenbach, Helmholtz, Kundt, Warburg, Maxwell, Reynolds, Knudsen, Klinkenberg, Kozeny, and Carman.

\section{Poiseuille Flow}

Starting with his Ph.D. thesis, Jean Léonard Marie Poiseuille depicted in Fig. 4 was interested in flow of human blood in narrow tubes. In 1838, he experimentally derived, and in 1840 and 1846 formulated and published, Poiseuille's law, now commonly known as the Hagen-Poiseuille equation, crediting Gotthilf Heinrich Ludwig Hagen as well. This law applies to laminar flow of liquids through tubes of uniform cross-section, such as flow of water in slim glass capillaries, or blood flow in capillaries and veins. In fact Poiseuille never derived "his" law as it was later named by the generous Hagenbach, who derived the actual hydrodynamic equation in 1860 .

By analyzing efflux from seven of his earlier experiments, Poiseuille only showed that the rate of mass flow is

$$
\dot{m}=K^{\prime \prime} P d^{4} / L=K^{\prime \prime \prime} \frac{\pi d^{4}}{4 \mu} \rho \frac{P}{L}
$$

$K^{\prime \prime}$ being a function of temperature and the type of fluid flowing. At $10^{\circ} \mathrm{C}$, his data yield

$$
K^{\prime \prime}=2495.224(\mathrm{mg} / \mathrm{s})\left[(\mathrm{mm} \mathrm{Hg}) \mathrm{mm}^{3}\right]^{-1}=18715.72 \mathrm{~kg}\left(\mathrm{~Pa} \mathrm{~s} \mathrm{~m}^{3}\right)^{-1}
$$

for distilled water. By deduction, one could factor out from the constant $K^{\prime \prime}$ the tube area, water density, and viscosity: $K^{\prime \prime}=\frac{\pi \rho}{4 \mu} K^{\prime \prime \prime}$. Assuming that the independently measured water density at $10^{\circ} \mathrm{C}$ and $1 \mathrm{~atm}$ is $\rho=999.75 \mathrm{~kg} \mathrm{~m}^{-3}$ and its viscosity is $\mu=1.305 \times 10^{-3}$ Pa s, the dimensionless $K^{\prime \prime \prime}=32.13^{-1}$ is very close to the theoretical value of $32^{-1}$. Our application of dimensional analysis, see Barenblatt (1996), to three sets of Poiseuille's data yields $C=32.14^{-1}$, see Fig. 5 . The complex story of Poiseuille's research and publications is nicely described in a review paper by Sutera and Skalk (1993), which in turn draws on the classical memoir by Bingham (1940).

Poiseuille Law. In Appendix A, we summarize the well-known derivation of Poiseuille's law by Bird et al. (1960). Here is a detailed list of the customary assumptions behind this derivation with a few changes and requalifications:

1. We consider a macroscopic flow of a fluid in a very long tube of length $L, L / d \gg 1, d=2 R, R$ being the tube radius.

2. The flow is creeping, i.e., the Reynolds number $\operatorname{Re}=d \rho\left\langle v_{z}\right\rangle / \mu \ll 1$. Here $\left\langle v_{z}\right\rangle$ is average flow velocity, $\rho$ is the fluid density, and $\mu$ is the viscosity.

3. From 1 and 2 it follows that end-effects can be neglected, because the entrance length of the order of $L_{e}=0.035 d \mathrm{Re}$ is very small compared with the tube length.

4. The flow is incompressible, $\rho=$ const, and if it is not, the flow velocity is so low that the momentum convection terms can be neglected. 
5. The flow is steady state, i.e., the flow velocity is independent of time.

6. The fluid is Newtonian, i.e., $\tau_{r z}=-\mu\left(d v_{z} / d r\right)$. Here $\tau_{r z}$ denotes the component of viscous stress tensor $\tau$ in the direction of $z$-axis, and perpendicular to the radial direction $r$.

7. The fluid behaves as a continuum, i.e., the molecular mean free path is much much less than the tube diameter and gas molecules are much more likely to collide with one another rather than with the tube wall. We will relax this assumption for the flow of gases in shales.

8. Therefore, there is no slip at the wall, $v_{z}(R)=0$. We will relax this boundary condition for the flow of gases.

Paraphrasing Wikipedia, we also remind that gas is a very special state of matter:

Gas is one of the four fundamental states of matter (the others being solid, liquid, and plasma). A pure gas may be made up of individual atoms (e.g. a noble gas like neon), elemental molecules made from one type of atom (e.g. oxygen), or compound molecules made from a variety of atoms (e.g. methane). A gas mixture contains a variety of pure gases much like the air or natural gas. What distinguishes a gas from liquids and solids is the vast separation of the individual gas molecules. This separation is measured by the mean free path, $\lambda$, of gas molecules and it usually makes a colorless gas invisible to the human observer.

Therefore the analogy of a large Knudsen number, devised originally for a very long $\lambda$ and a large characteristic length of the solid, $R$, but such that the ratio $\lambda / R$ is large, breaks down when both $\lambda$ and $R$ are close to the size of gas molecules, but their ratio is still large. Professor Barenblatt $(1994,1996)$ has taught us that all similarity theories are in fact intermediate asymptotics, and break down near the physical limitations on the sizes of important system parts. This is, in a nutshell, the reason for our doubts about the applicability to mudrocks of the Knudsen-like scalings developed for the rarified gases in large tubes or the super-rarified air pierced by the missiles traveling ten times the speed of sound. The dense supercritical fluid in shale pores is more akin to a liquid, rather than to a rarified gas.

In Appendix A, we show that the average fluid flow velocity is

$$
\left\langle v_{z}\right\rangle=\frac{\left(\Phi_{0}-\Phi_{L}\right) R^{2}}{8 \mu L}
$$

and the volumetric flow rate is

$$
Q=\left\langle v_{z}\right\rangle \pi R^{2}=\frac{\left(\Phi_{0}-\Phi_{L}\right) \pi R^{4}}{8 \mu L}
$$

where $\Phi$ is the flow potential defined in Eq. (A9). The last equation is the famous Hagen-Poiseuille formula.

Now suppose that fluid is compressible. For simplicity, let's assume that the fluid is an ideal gas and the tube is horizontal. The flow is so slow that we can neglect the momentum convection terms in Eqs. (A3) and (A4). If these terms cannot be neglected, there is no analytic solution. The shell in Figure A1 can be shortened along the tube axis to a segment $d z$ long. Then the Hagen-Poiseuille formula can be written in the differential and integrated forms as:

$$
\begin{aligned}
\dot{m} & =Q \rho=-\frac{\pi R^{4}}{8 \mu} \rho \frac{\mathrm{d} P}{\mathrm{~d} z} \quad \frac{\mathrm{kg}}{\mathrm{s}} \\
\rho & =\frac{P}{R_{g} T} \quad \frac{\mathrm{kg}}{\mathrm{m}^{3}} \\
\dot{m} & =-\frac{\pi R^{4}}{8 \mu} \frac{1}{R_{g} T} P \frac{\mathrm{d} P}{\mathrm{~d} z}=\frac{\pi R^{4}}{16 \mu L} \frac{1}{R_{g} T}\left(P_{0}^{2}-P_{L}^{2}\right)=\frac{\pi R^{4}}{8 \mu L} \rho_{m}\left(P_{0}-P_{L}\right) \\
\rho_{m} & =\frac{P_{0}+P_{L}}{2 R_{g} T}
\end{aligned}
$$

where $R_{g}$ is the specific gas constant in $\mathrm{kJ} \mathrm{kg}^{-1} \mathrm{~K}^{-1}$ and $\rho_{m}$ is the gas density at the mean pressure. 


\section{Mean Free Paths of Gas Molecules}

A simple expression for the mean free path can be derived from elementary kinetic theory, see, e.g., Maxwell (1868), Hirschfelder et al. (1954), Reif (1998):

$$
\lambda=\frac{k_{B} T}{\sqrt{2} \sigma P}
$$

where $\sigma=\pi d^{2}$ is the effective cross-sectional area for molecular collisions.

Prausnitz and Benson (1959) calculate effective collision diameters $d$ for several gases based on the kinetic theory of gases, Hirschfelder et al. (1954), see Table 1.

Table 1: Effective collision diameters for gases

\begin{tabular}{r|ccc}
\hline Component & $\mathrm{CO}_{2}$ & $\mathrm{~N}_{2}$ & $\mathrm{CH}_{4}$ \\
$d(\AA)$ & 3.68 & 3.77 & 3.89 \\
\hline
\end{tabular}

Brown et al. (1946) and Javadpour (2009) used the following expression for the mean free path:

$$
\lambda=\sqrt{\frac{\pi R T}{2 M}} \frac{\mu}{P}
$$

where $\mathcal{R}=8314 \mathrm{~J}(\mathrm{kmol} \mathrm{K})^{-1}$ is the universal gas constant, $M \mathrm{~kg} \mathrm{kmol}^{-1}$ is the molar mass of gas, $T \mathrm{~K}$ is the gas temperature, and $\mu \mathrm{Pa}$ is the gas viscosity.

Roy et al. (2003) in turn used yet another variant of the Chapman-Enskog theory, Hirschfelder et al. (1954):

$$
\lambda=\sqrt{\frac{\pi M}{2 R T}} \frac{\mu}{\rho}
$$

where $\rho \mathrm{kg} \mathrm{m}^{-3}$ is the gas density.

The gas density was calculated using tuned SRK EOS and a tuned viscosity correlation for the natural gas described in Patzek et al. (2014).

Equations (7) - (9) are based on the same kinetic theory of gases for low and intermediate pressures, and yield practically identical results, see Fig. 6. The last two equations have three governing variables and show effects of high gas pressure. Note that all three curves in Fig. 6 are cut off at the diameter of a single methane molecule. The natural gas molecules at high pressures become increasingly packed and the Poiseuille law with slip that is commonly used to explain their flow must fail, as much as the very expressions for the $\lambda$ fail.

In summary, for a typical mudrock, the initial reservoir pressure can be 250 bars or more, the temperature $100-200^{\circ}$ $\mathrm{C}$, and the mean free path of methane molecules is $\lambda \approx 0.3 \mathrm{~nm}$, less than the collision size of these molecules. We conclude that even at the hydrofracture face pressure, the mean free paths of gas molecules are of the order of $1 \mathrm{~nm}$; at the reservoir conditions they are shorter than $1 \mathrm{~nm}$, see Fig. 6. In very small pores, $R \leq 5 \mathrm{~nm}$, even methane molecules become more ordered and liquid-like, and flow without slip.

\section{Slip Flow}

In the small-scale, low-velocity flows of gases, the failure of the standard Navier-Stokes description can be quantified by the KNUDSEN number, Knudsen (1909, 1995):

$$
\mathrm{Kn}=\frac{\lambda}{\ell}
$$


where $\lambda$ is the molecular mean free path calculated at a pressure that characterizes the flow, and $\ell$ is the characteristic hydrodynamic length scale, here the capillary tube radius $R$ (or diameter $d$ ).

Hadjiconstantinou (2006), who followed in the footsteps of Roy et al. (2003), wrote:

For small Knudsen numbers, kinetic effects at the walls manifest themselves, at the Navier-Stokes description level, in the form of "apparent" hydrodynamic property slip/jump at the boundaries which can be captured by slip-flow boundary conditions. For $\mathrm{Kn} \lesssim 1$ a first-order asymptotic theory is sufficiently accurate, especially for practical purposes ${ }^{3}$. For this reason, the regime $\mathrm{Kn} \lesssim 1$ is known as slip flow. It is noteworthy that for $\mathrm{Kn}$ $\ll 1$ Knudsen layers are present irrespective of the characteristic system length scale, $\ell$; however, as Kn decreases, their effect becomes less pronounced, as one would expect, to the extent that in the limit $\mathrm{Kn} \lll 1$ their effect is, for all practical purposes, negligible and the classical no-slip boundary condition becomes an excellent approximation ${ }^{4}$.

As if though the imprecise notations in the literature were not bad enough, the slip boundary condition depends on $\lambda$ multiplied a function of the "accommodation coefficient f" defined by Maxwell, Niven (1890), and explained below. For most surfaces in contact with gas this function is about one, Niven (1890), Kundt and Warburg (1875), Knudsen (1909), Wenski et al. (1998), Hadjiconstantinou (2006), but on some surfaces it can be much more than one, Brown et al. (1946). Here we maintain that for the rough rock walls $f \approx 1$, and only $\lambda$ enters the appropriate slip velocity boundary condition. In summary, with $f \approx 1$, we define the regimes of creeping gas flow in capillaries as

$$
\mathrm{Kn}\left\{\begin{array}{l}
\leq 0.01 \quad \text { Poiseuille flow with no-slip condition } \\
>0.01 \text { but } \leq 1 \quad \text { Slip flow } \\
>1 \text { but }<10 \quad \text { Transition flow } \\
>10 \quad \text { Molecular or ballistic flow }
\end{array}\right.
$$

Note that in the current classification, all flow regions are shifted upwards by a factor of 10 or 100 relative to the definitions proposed by Javadpour et al. (2007), who based their classification on the admittedly imprecise papers by Roy et al. (2003), Hadjiconstantinou (2006), who attempted to translate the equations of aerodynamics into very different physical situations:

$$
\mathrm{Kn}\left\{\begin{array}{l}
\leq 0.001 \quad \text { Poiseuille flow with no-slip condition } \\
>0.001 \text { but } \leq 0.1 \quad \text { Slip flow } \\
>0.1 \quad \text { Molecular or ballistic flow }
\end{array}\right.
$$

Based on the discussion of slip-velocity that follows, we assert that Javadpour's classification (12) is inconsistent with the flow physics. Unfortunately, the latter classification has been widely accepted in the petroleum industry. In his 2009 paper, Javadpour (2009) refers only to the 1946 paper by Brown et al. (1946), which deals with the flow of gases in large industrial metal pipes, elbows and orifices under vacuum, with gas pressures of the order of $1 \mathrm{~mm} \mathrm{Hg}$ or less. The slip flow velocity correction factor F in Brown et al. (1946), replicated as Eq. (13) in Javadpour (2009), is

$$
F=1+\sqrt{\frac{8 \pi \mathcal{R} T}{M}} \frac{\mu}{P_{m}} \frac{4}{R}\left(\frac{2}{f}-1\right)=1+4\left(\frac{2}{f}-1\right) \frac{\lambda_{m}}{R}=1+4\left(\frac{2}{f}-1\right) \mathrm{Kn}_{m}
$$

\footnotetext{
${ }^{3}$ The notations $x \lesssim 1, x \ll 1$, and $x \lll 1$ are gravely imprecise. We define the first notation as " $x$ less or about 1, " i.e., $0.1<x \leq 1$. The second one is defined as " $x$ is less than one by at least one order of magnitude," i.e., $x \leq 0.1$. The third notation is defined as " $x$ is less than one by at least two orders of magnitude," i.e., $x \leq 0.01$.

${ }^{4}$ The questions we need to ask are: Do the observed effects justify keeping a simplified first-order model? Is the slip-flow correction justified? Notice that an operational definition of "justification" depends on how closely one needs to look and how feasible it is to look even deeper.
} 
where $\mathcal{R}$ is the universal gas constant, $M$ is the molecular weight of natural gas, $\mu$ the gas viscosity, $P_{m}$ the mean gas pressure, and $f \approx 1$ for rock materials. This factor is plotted in Fig. 7 for the natural gas described in Patzek et al. (2014). We have adjusted the leading coefficient from 4 to $8 / 3$, as discussed below. The formation temperature is $T=100^{\circ} \mathrm{C}$, the pore radii are $R=5,10$ and $50 \mathrm{~nm}$, and $f=1^{5}$. The bottom line is that for in the compressed natural gas at field conditions the $F$-factor is less than two even for very small pores according to the correctly interpreted equations in Javadpour (2009). For the $R=1-2 \mathrm{~nm}$ pores the $F$-factor would be more than 5 , but the theory of flow we use here fails.

If the median pore radius is $R_{\text {median }}=50 \mathrm{~nm}$, the ratio of $\lambda / R_{\text {median }}$ is less than 0.1 for pressures exceeding 60 bars, see Fig. 8. Let's compare the actual slip-flow correction in Fig. 7 with our classification of flow regimes, Eq. (11). From this comparison it appears that the classification (11) is conservative for pores larger that $10 \mathrm{~nm}$ in radius.

To summarize, we cannot have it both ways. If we insist on the cylindrical capillary analogy for gas flow in mudrocks, the slip correction is either mostly irrelevant for larger pores or inappropriate for smaller pores. Since the increase of effective permeability to gas flow in mudrocks is real, we must invoke other pore geometries and admit that many, perhaps thousands, of really small nanopores packed with liquid-like dense gas connect to micropores.

Let us consider the following thought experiment. Assume that a cylindrical micropore has radius, $R_{\text {micro }}=100 \mathrm{~nm}$, and length $L_{\text {micro }}=5 R_{\text {micro }}$. The cylindrical surface of this pore is pock-marked with nanopores of $R_{\text {nano }}=4 \mathrm{~nm}$ each centered in each dark square on a chessboard partitioned into squares of length $3 R_{\text {nano, }}$, see Fig. 3 . There will be $N=$ $\pi R_{\text {micro }}^{2} L_{\text {micro }} /(3 R)_{\text {nano }}^{2} / 2 \approx 1000$ of these nanopores associated with the micropore. The macro and micropores are inside of a parallelepiped of volume $V=4\left(R_{\text {micro }}+5 R_{\text {nano }}\right)^{2} L_{\text {micro }}$. The specific surface area of the micropore is

$$
a_{\mathrm{v}, \text { micro }}=\frac{2 \pi R_{\text {micro }} L_{\text {micro }}}{V}=0.014 \mathrm{~nm}^{-1}
$$

The specific surface area of the nanopores and the micropore is

$$
a_{\mathrm{v}, \text { all }}=a_{\mathrm{v}, \text { micro }}+\frac{2 \pi R_{\mathrm{nano}}\left(5 R_{\mathrm{nano}}\right)}{V}=0.039 \mathrm{~nm}^{-1}
$$

almost three times more. Note that with this nanopore arrangement the added surface area does not depend on the nanopore radius because the product of the number of dark squares and $R_{\text {nano }}^{2}$ is a geometric constant. Now please reread the last paragraph of our quote of Dr. Muskat reflecting of Dr. Klinkenberg's paper.

\section{A Historical Note}

Kundt and Warburg (1875) modified the Poiseuille's equation by increasing the flow velocity of the gas at the tube wall from zero (the no-slip condition) to a positive value, $u_{0}$, when the mean free path of gas molecules, $\lambda$, is comparable with the tube radius. The resulting tangential drag force $d F^{\prime}$ per unit area of the wall was assumed to be proportional to $u_{0}$ :

$$
\frac{\mathrm{d} F^{\prime}}{\mathrm{d} A_{w}}=k u_{0}
$$

They called the proportionality constant, $k \mathrm{~Pa} \mathrm{~s} \mathrm{~m}^{-1}$, the coefficient of external friction. Therefore

$$
\begin{aligned}
-\pi R^{2} d P & =k u_{0}(2 \pi R d z) \\
u_{0} & =-\frac{k}{2 R} \frac{\mathrm{d} P}{\mathrm{~d} z}=\frac{k}{2 R} \frac{\Delta P}{L}
\end{aligned}
$$

\footnotetext{
${ }^{5}$ Javadpour (2009) fitted the high flow rate data from Roy et al. (2003) with $f=0.8$.
} 
By setting $v_{z}(R)=u_{0}$ in Eq. (A14) we obtain

$$
\begin{aligned}
u_{0} & =-\left(\frac{\Delta P}{4 \mu L}\right) R^{2}+C_{2} \\
C_{2} & =\frac{\Delta P}{4 \mu L} R^{2}\left(1+\frac{2 \mu}{k R}\right) \\
v_{z} & =\left(\frac{\Delta P}{4 \mu L}\right) R^{2}\left[1-\left(\frac{r}{R}\right)^{2}+\frac{2 \mu}{k R}\right] \\
\left\langle v_{z}\right\rangle & =\frac{\Delta P R^{2}}{8 \mu L}\left(1+\frac{4 \mu}{k R}\right) \\
\dot{m} & =\frac{\pi \Delta P R^{4}}{8 \mu L} \rho_{m}\left(1+\frac{4 \mu}{k R}\right)
\end{aligned}
$$

James Clerk Maxwell, Fig. 9, (Niven 1890; On the Conditions to be Satisfied by a Gas at the Surface of a Solid Body, pp. 704-712) wrote:

We might also consider a surface on which there are a great number of minute asperities of any given form, but since in this case there is considerable difficulty in calculating the effect when the direction of rebound from the first impact is such as to lead to a second or third impact, I have preferred to treat the surface as something intermediate between a perfectly reflecting and a perfectly absorbing surface, and, in particular, to suppose that of every unit of area a portion $f$ absorbs all the incident molecules, and afterwards allows them to evaporate with velocities corresponding to those in still gas at the temperature of the solid, while a portion $1-f$ perfectly reflects all the molecules incident upon it.

Today we refer to the fraction $f$ of the gas molecules striking the wall as diffusely reflected, and the fraction $1-f$ as specularly reflected, see Fig. 10.

Maxwell continued:

If there is no inequality of temperature, this equation ${ }^{6}$ is reduced to

$$
v=G \frac{\partial v}{\partial x}, \quad v=\text { the velocity component in the } y \text {-direction }
$$

If, therefore, the gas at a finite distance from the surface is moving parallel to the surface, the gas in contact with the surface will be sliding over it with the finite velocity $v$, and the motion of the gas will be very nearly the same as if the stratum of depth $G$ had been removed from the solid and filled with the gas, there being now no slipping between the new surface of the solid and the gas in contact with it. The coefficient $G$ was introduced by Helmholtz, Fig. 11, and his student Piotrowski, Helmholtz and von Piotrowski (1860) under the name of Gleitungs-coefficient, or coefficient of slipping. The dimensions of $G$ are those of a line, and its ratio to $\lambda$, the mean free path of a molecule, is given by the equation

$$
G=\frac{2}{3}\left(\frac{2}{f}-1\right) \lambda
$$

Kundt and Warburg found that for air in contact with glass, $G=2 \lambda$, whence we find $f=1 / 2$, or the surface acts as if it were half perfectly reflecting and half perfectly absorbent. If it were wholly absorbent, $G=2 / 3 \lambda$.

\footnotetext{
${ }^{6} \mathrm{Of} v$, the $y$-component of the gas velocity at the $y z$ plane oriented by the normal in the $+x$-direction.
} 
Maxwell then proceeded to derive the Poiseuille's law for creeping flow in a capillary tube of radius ${ }^{7} R$ and with a slip-velocity boundary condition at the tube wall. In our notation:

$$
\dot{m}=\frac{\pi \Delta P R^{4}}{8 \mu L} \rho_{m}\left(1+\frac{4 G}{R}\right)
$$

Maxwell's equation (19) is not the same as the one in Brown et al. (1946), propagated through the subsequent literature, notably to Javadpour (2009).

If we set the leading coefficient in Eq. (18) to one, as in Brown et al. (1946),

$$
G=\frac{\mu}{k}=\left(\frac{2}{f}-1\right) \lambda_{m}
$$

and we recover Eq. (13). If we stay with the original derivation of the Gleitungs-coefficient in Helmholtz and von Piotrowski (1860), admittedly for planes, we get

$$
F=1+\frac{8}{3}\left(\frac{2}{f}-1\right) \mathrm{Kn}_{m}
$$

More mathematical analysis must be performed to determine the leading constant in the Gleitungs-coefficient for cylindrical capillaries. For $K n \ll 1$ the $2 / 3$ coefficient is obviously correct because locally the cylinder appears to be flat to the impinging molecules. For $\mathrm{Kn} \approx 1$, the cylindrical surface is curved and more molecules will impinge upon it. The viscous drag $k$ will then increase, and $G$ will decrease. In this case the slip correction in Eq. (21) will be smaller, making the flow regime classifications (11) and (12) even more illusory.

Since the coefficient of external friction, $k$, has been found Kundt and Warburg (1875) to be proportional to gas pressure, its value and that of $\lambda_{m}$ should be evaluated at the mean gas pressure.

Inspection of Eq. (19) shows that this equation for "slip flow" is essentially Poiseuille's equation (6) multiplied by a correction factor which becomes more important as the ratio of mean free path to radius increases and as $f$ becomes small (smooth tube walls).

The mudrock pore walls are anything but smooth, therefore one would expect $f \rightarrow 1$, and

$$
G=\frac{\mu}{k} \approx \lambda_{m}
$$

if we can treat pores in shales as capillaries of sufficient length. For short "bubble pores," $L / d \approx 1$, and the fluid flow in these pores may not follow the Poiseuille's law, but perhaps flow through orifices.

If the capillaries are short, and gas pressure low, Maxwell warns:

These effects of the variation of temperature in a tube have been pointed out by Professor Osborne Reynolds as a result of the Kinetic Theory of Gases, and have received from him the name of Thermal Transpiration: a name in strict analogy with the use of the word Transpiration by Graham (1995). But the phenomenon actually observed by Professor Reynolds in his experiments was the passage of gas through a porous plate, not through a capillary tube; and the passage of gases through porous plates, as was shown by Graham, is of an entirely different kind from the passage of gases through capillary tubes, and is more nearly analogous to the flow of a gas through a small hole in a thin plate.

\footnotetext{
${ }^{7} a$ in Maxwell's notation.
} 
When the diameter of the hole and the thickness of the plate are both small compared with the length of the free path of a molecule, then, as Sir William Thomson has shown, any molecule which comes up to the hole on either side will be in very little danger of encountering another molecule before it has got fairly through to the other side. Hence the flow of gas in either direction through the hole will take place very nearly in the same manner as if there had been a vacuum on the other side of the hole, and this whether the gas on the other side of the hole is of the same or of a different kind.

\section{Discussion and Conclusions}

In order to model gas flow in a mudrock system at pore scale, one needs a fairly complete description of geometry and connectivity of the flow network. To use the angular cylindrical capillary analogy for each pore body, a representative shape factor (ratio of pore cross-sectional area to the square of perimeter), inscribed circle radius, length, and coordination number must be known, Øren et al. (1998), Patzek (2001). The same parameters must also be known for each pore throat connecting this pore body to other pores. It is well-known that the slit-like, angular capillaries can have hydraulic conductances that are much smaller than those of circular cylinders, Patzek and Silin (2001). A multiscale topological description of volumetric rock images with a hierarchy of inscribed spheres, Silin and Patzek (2006), allows one to perform direct lattice Boltzmann calculations of fluid flow, Jin et al. (2004).

Mudrocks are essentially multiscale, see Eq. (1); have complex pore shapes, e.g., Loucks et al. (2012); and currently their pore level description is incomplete. Even "pore size" determinations are ill-defined, inconsistent, and often incomplete. A two-scale pore network model by Mehmani et al. (2013) is a useful attempt to capture some of the physics of gas flow in shales. This network shows a strong dependence of gas permeability on pressure, but it does not include the dozens or hundreds of nanopores that feed each micro- or mesopore, as in Fig. 3.

We conclude that in the smallest nanopores flowing gas would slip, if it did not behave more like a liquid. In the larger nanopores, at high reservoir pressure, the effect of slip is limited and likely smaller than uncertainty in the determination of absolute permeability and the permeability's dependance on pore pressure. Therefore, amending the macroscopic Darcy equation with an ad hoc "Knudsen diffusion" term seems to lack predictive capability and is likely unwarranted. We started addressing this problem some time ago, Islam and Patzek (2014).

To account for permeability increase in gas flow, inclusion of gas transport through the porous walls of micro- and mesoscale capillaries might be useful. In a subsequent paper, we will propose a model of gas transport from nano- to micropores. 


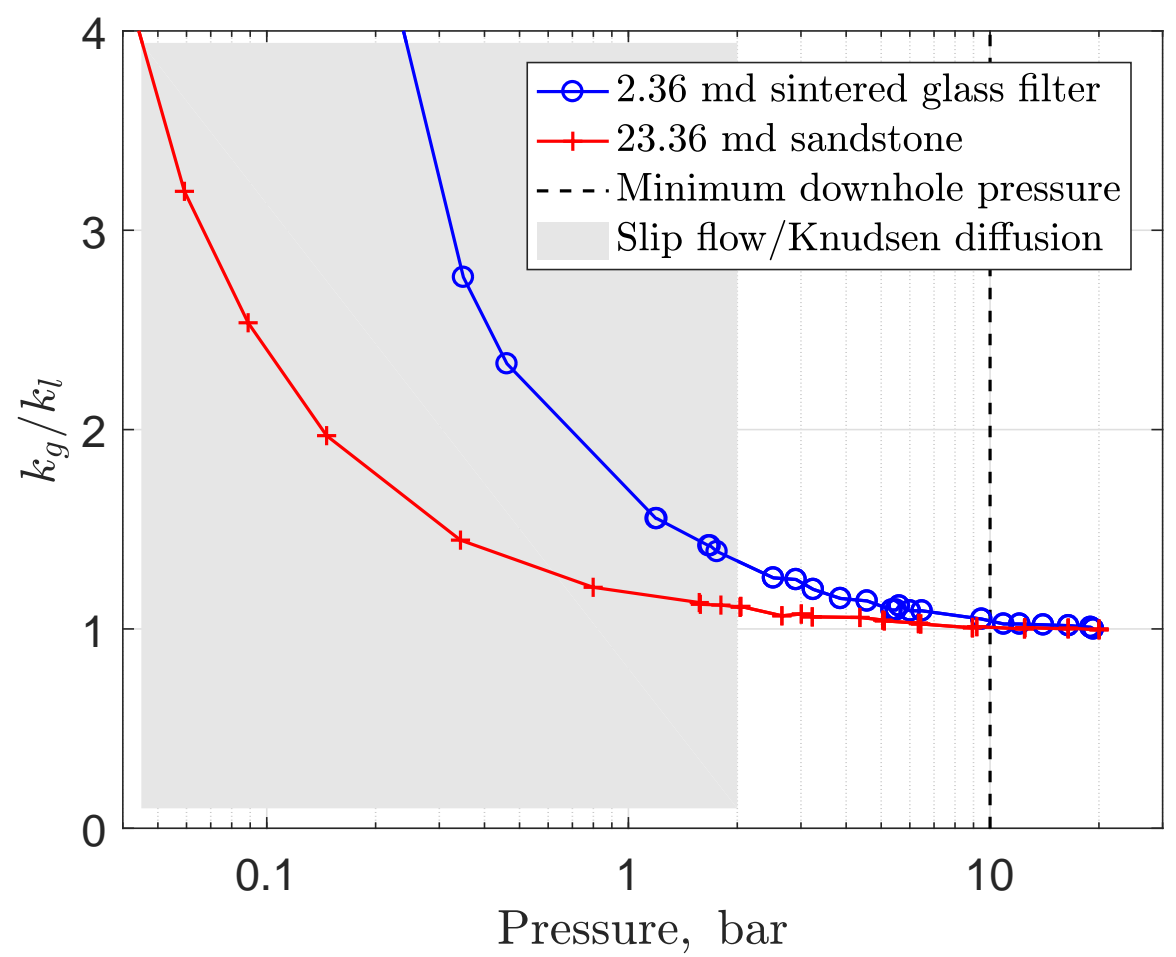

Figure 1: Air permeability measurements in a Jena sintered glass filter and in a sandstone core plug. These pioneering experiments were conducted by a Shell Development researcher Klinkenberg (1941). He demonstrated that at low gas pressures permeability to gas differs substantially from that to liquid because of slip flow. The slip effect increased with decreasing permeability. At pressures of the order of 10 bars (150 psi), the slip flow effect disappeared.

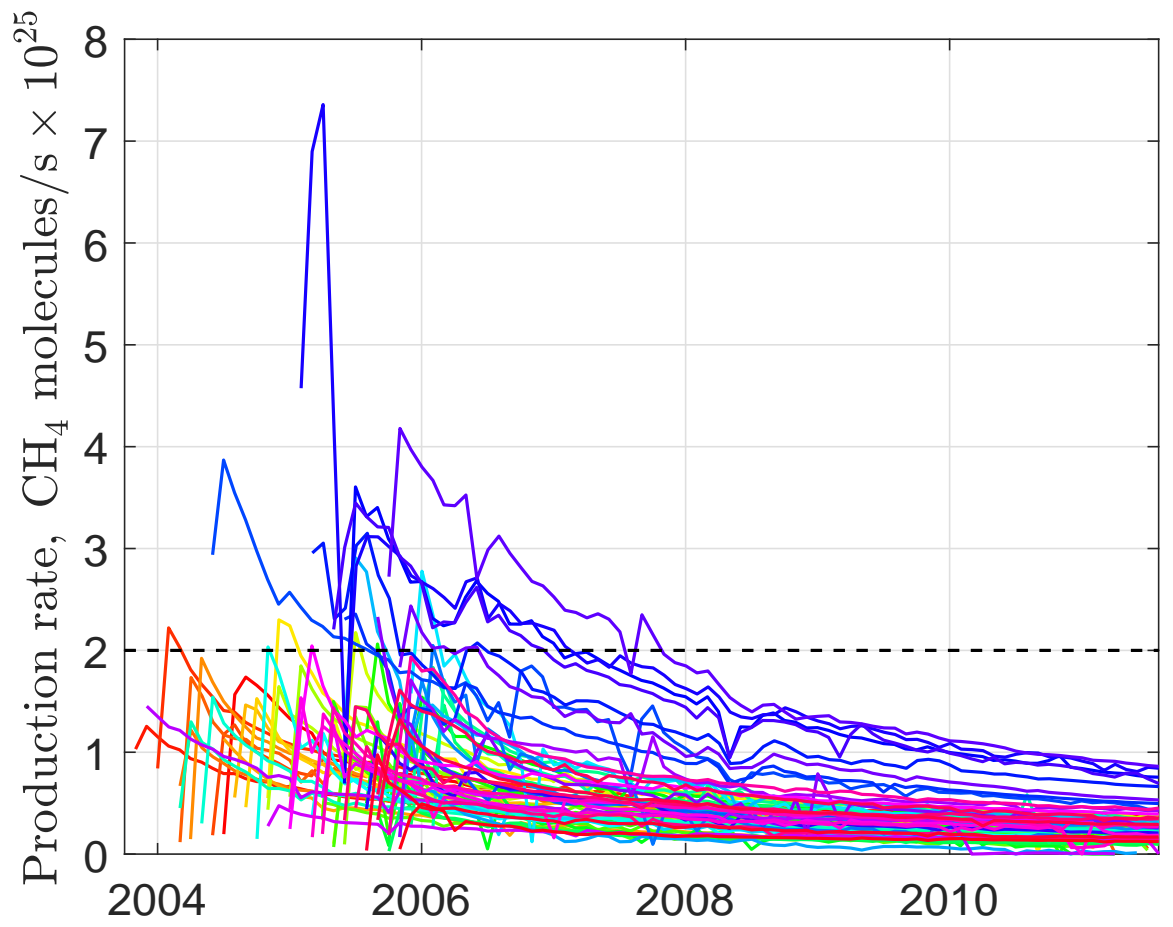

Figure 2: A decent horizontal well in the Barnett shale, Patzek et al. (2014), might produce $2 \times 10^{25}$ methane molecules per second $(33 \mathrm{~mol} / \mathrm{s})$ for $2-3$ years. 

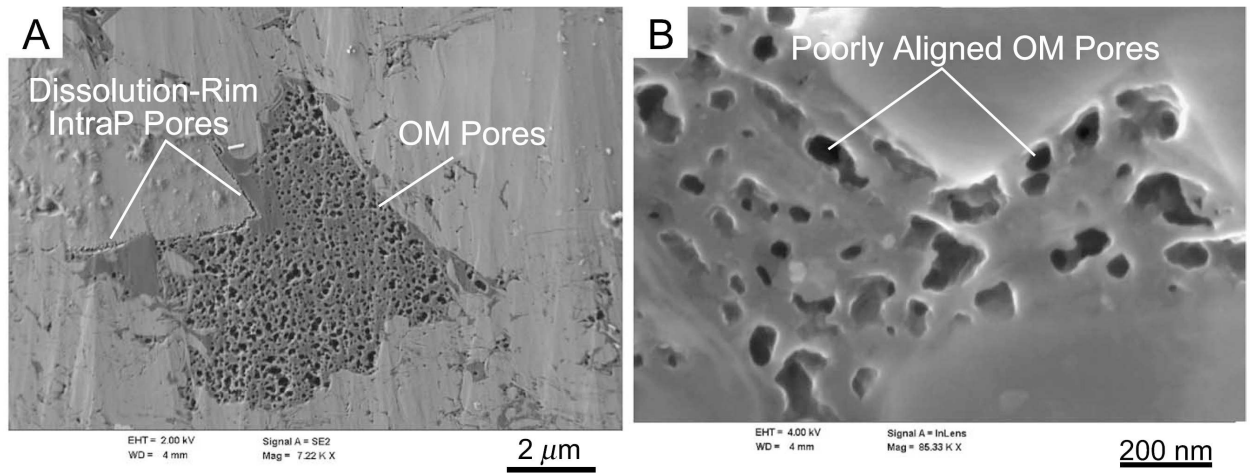

Figure 3: Example of organic-matter (OM) pores within mudrocks. (A) Large OM particle with OM pores. On the basis of point counting with 1000 points, this grain has a porosity value of $41 \% ; 7625 \mathrm{ft}(2324 \mathrm{~m})$, vitrinite reflectance (Ro) = approximately 1.6\%, Mississippian Barnett Shale, Wise County, Texas. (B) Organic-matter pores slightly aligned and showing complexity in third dimension; $7625 \mathrm{ft}$ (2324 m), approximately 1.6\% Ro, Mississippian Barnett Shale, Wise County, Texas. Reproduced from Figure 10 in Loucks et al. (2012) with permission.

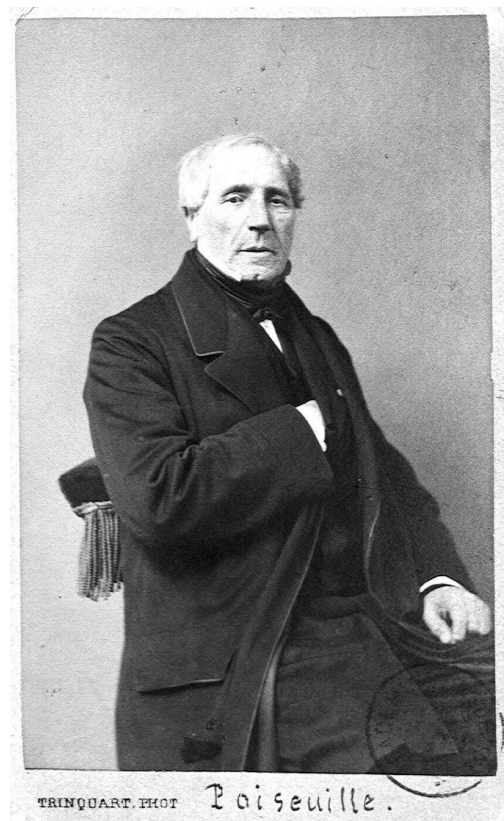

Figure 4: Jean Léonard Marie Poiseuille was born on Apr 22, 1797, and died on Dec 26, 1869. He was a French physicist and physiologist. 


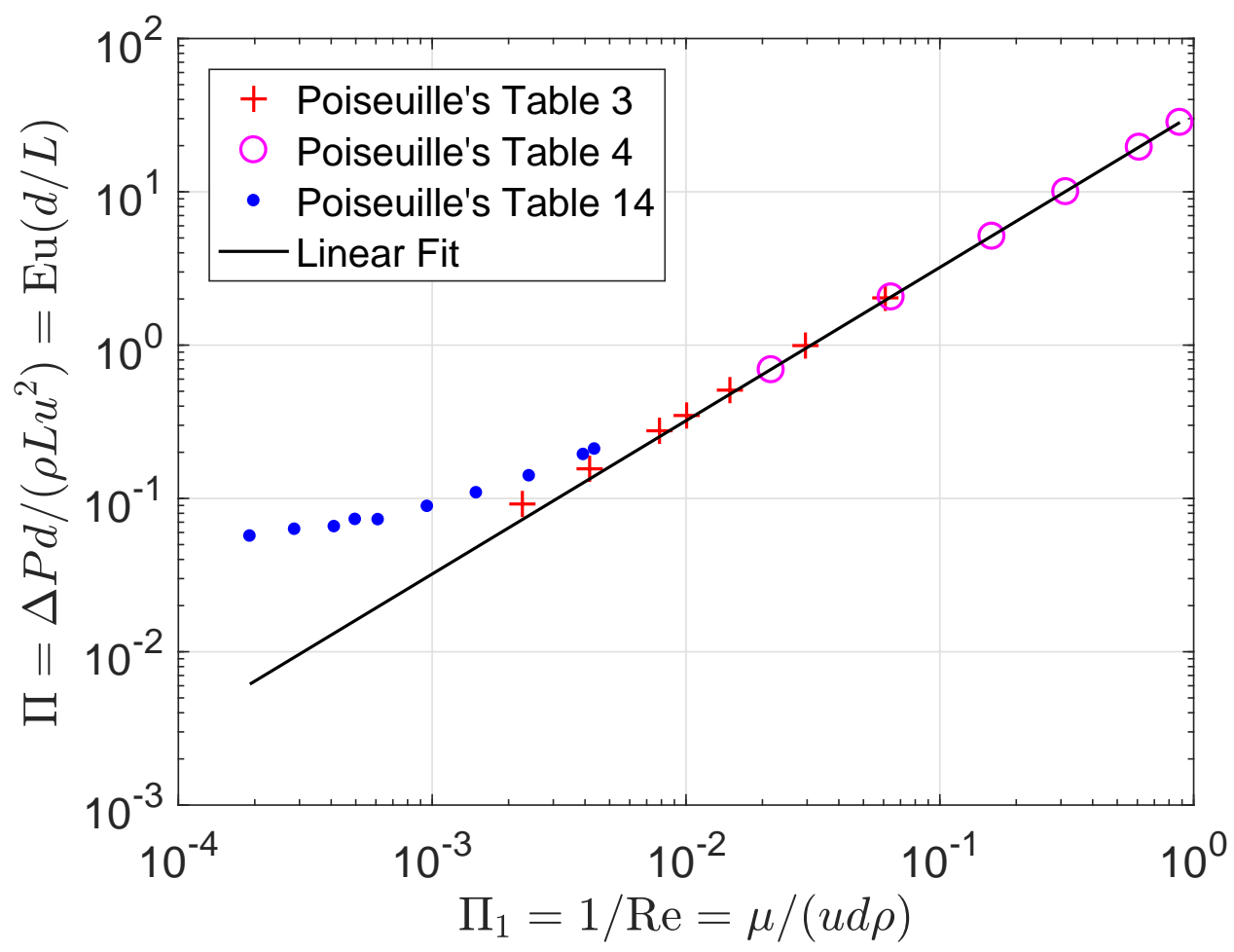

Figure 5: Fit of capillary discharge data in Poiseuille's Tables 3, 14, and 4, Bingham (1940). Using dimensional analysis we fit the dependent variable, $\Pi$, as a linear function of the inverse of Reynolds number, $u \rho d / \mu$, with zero intercept, $\Pi=\Phi\left(\Pi_{1}\right)=C /$ Re. The fit coefficient is $C=32.14$. The slightly turbulent flow data from Table 14 are also included in the regression.

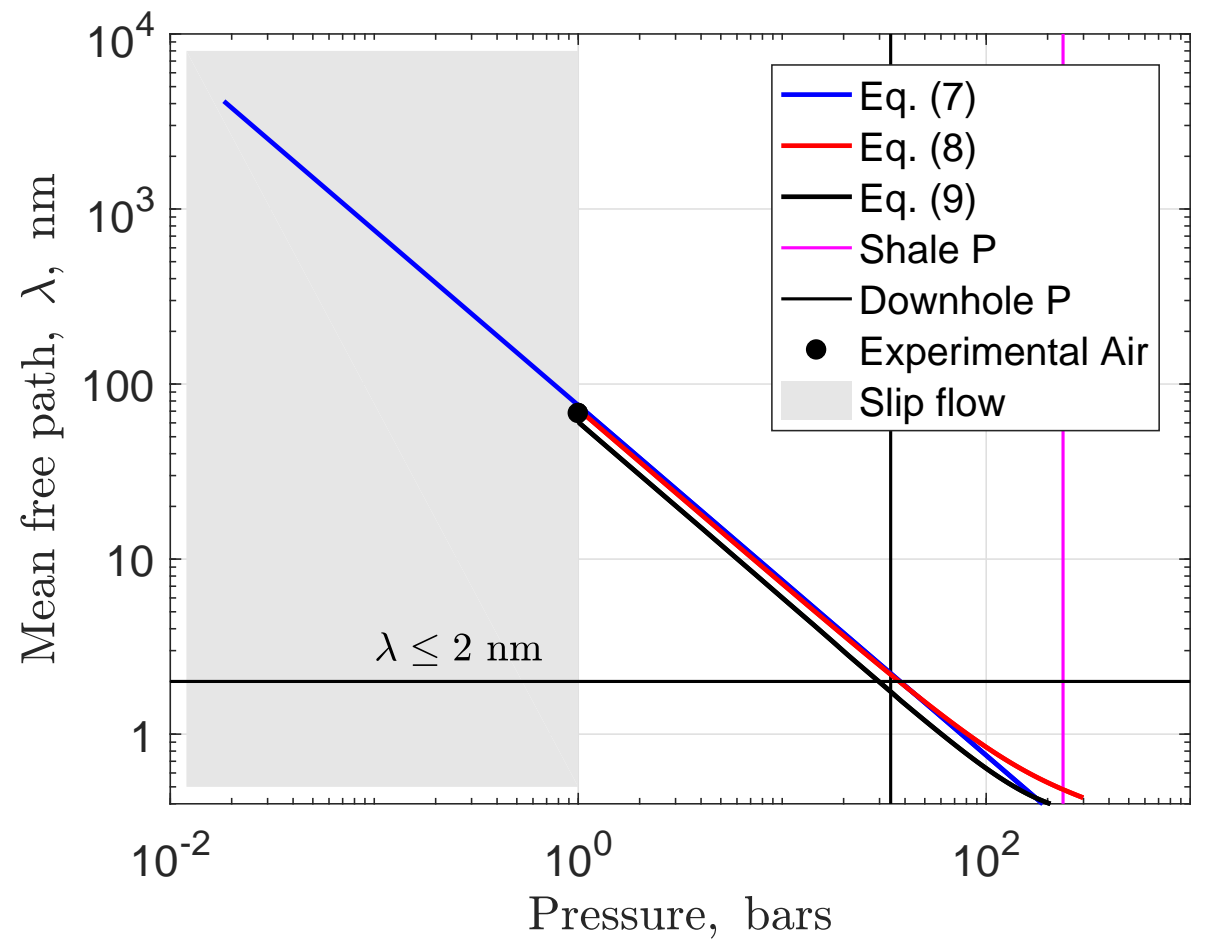

Figure 6: Mean free paths of methane vs. pressure at $100^{\circ} \mathrm{C}$ calculated from different equations. A typical reservoir pressure is indicated by the vertical red line and a downhole pressure by black line. There is no slip flow at reservoir conditions. 


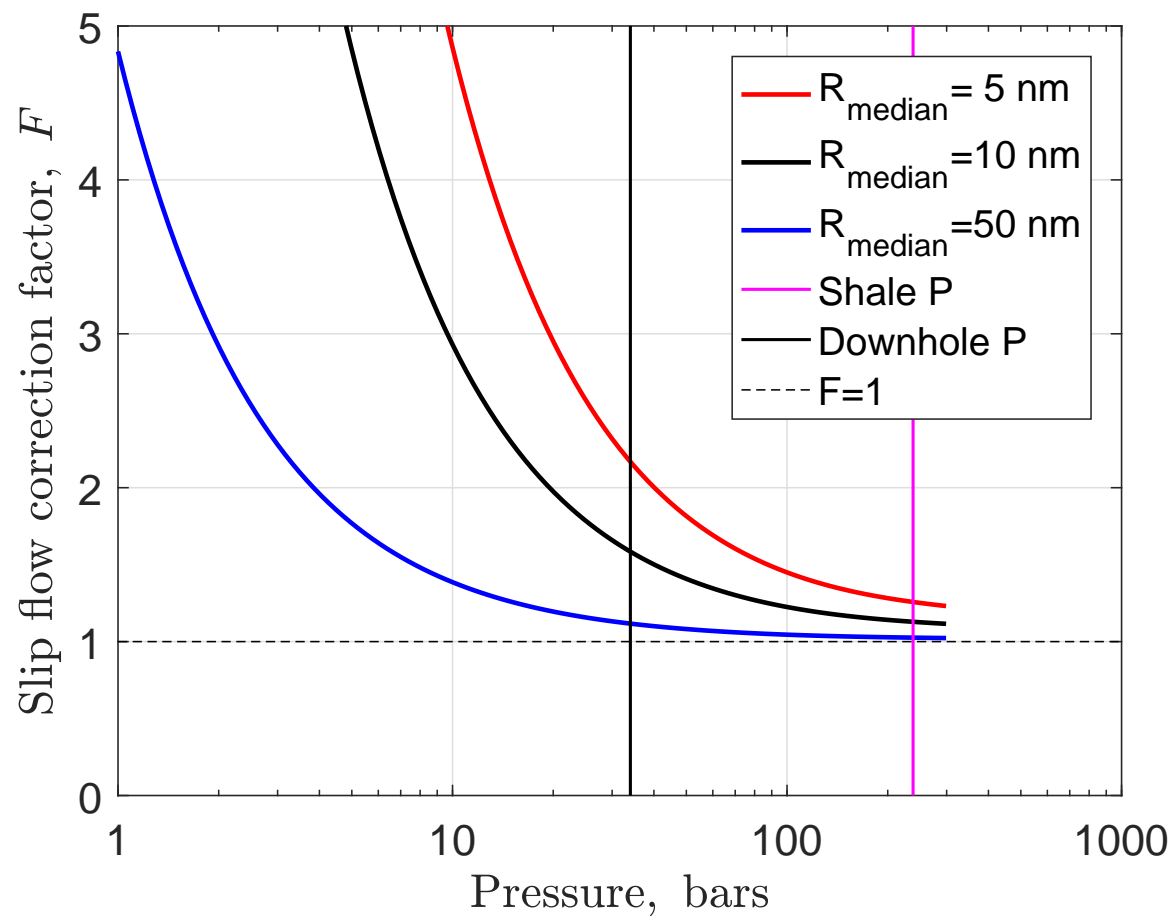

Figure 7: The slip flow correction factor, Eq. (14) in Brown et al. (1946), plotted for methane between a typical downhole pressure and reservoir pressure in the Barnett shale. Maxwell's equation (21) is used to calculate $F$ with $f=1$. This correction significantly exaggerates slip in the dense supercritical liquid-like gas with exceedingly short $\lambda s$.

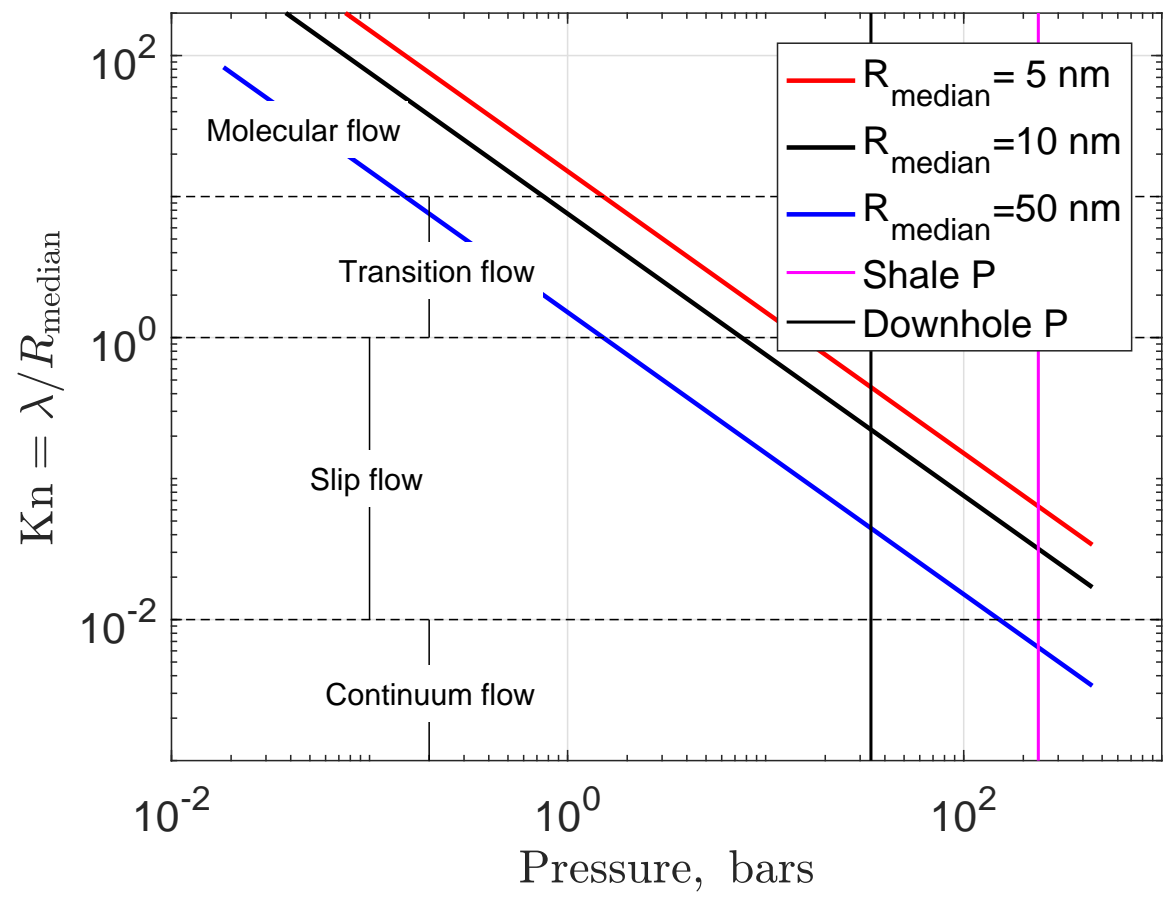

Figure 8: The ratio of mean free path of methane divided by $R_{\text {median }}$ vs. pressure at $100^{\circ}$ Celsius. A typical reservoir pressure is indicated by the right vertical line and a typical downhole pressure (fracture face pressure) by the left vertical line. Note that according to the classification (11), methane is mostly in the slip-flow regime. 


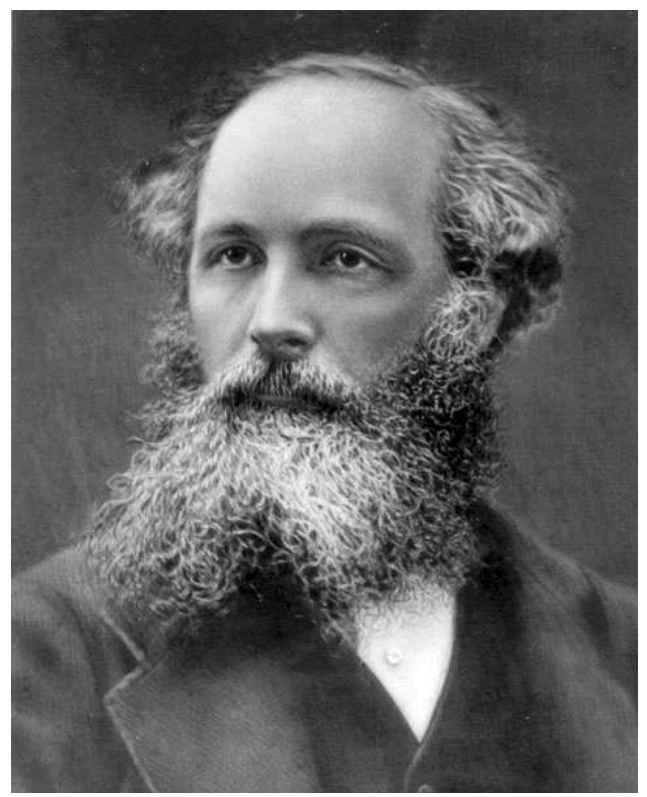

Figure 9: James Clerk Maxwell was born on Jun 13, 1831, and died Nov 5, 1879. Maxwell was a Scottish mathematical physicist, who formulated the classical theory of electromagnetic radiation bringing together for the first time electricity, magnetism, and light as manifestations of the same phenomenon. He was one of the best physicists of all times.

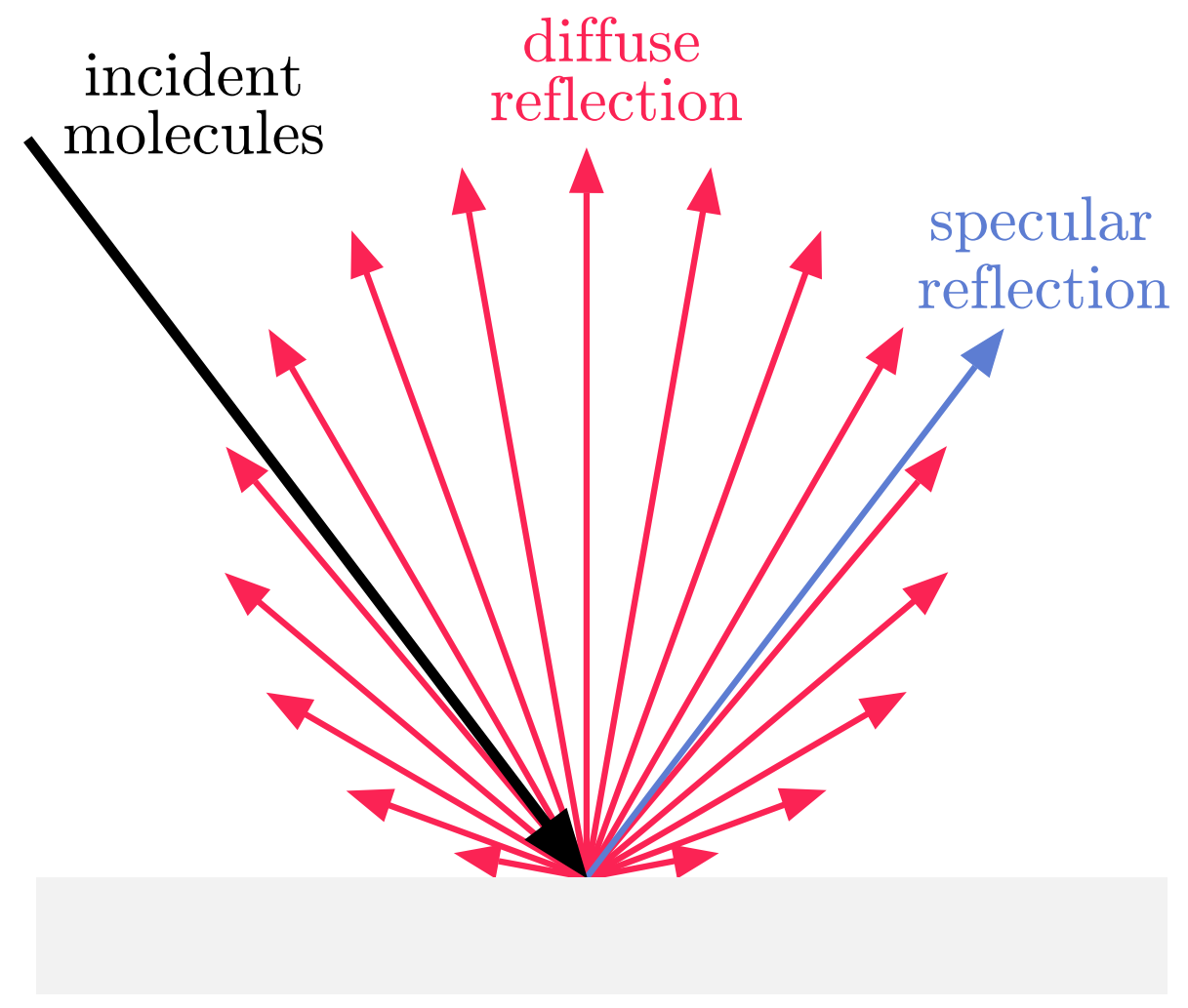

Figure 10: Specular and diffuse reflections. Rough, finely textured rock surfaces generate a large diffuse reflection component, $f \rightarrow 1$. Figure adapted from Diffuse and Specular Reflection by Peter Katz, May 5, 2012, photorealizer.blogspot.com/2012/05/diffuse-and-specular-reflection.html 


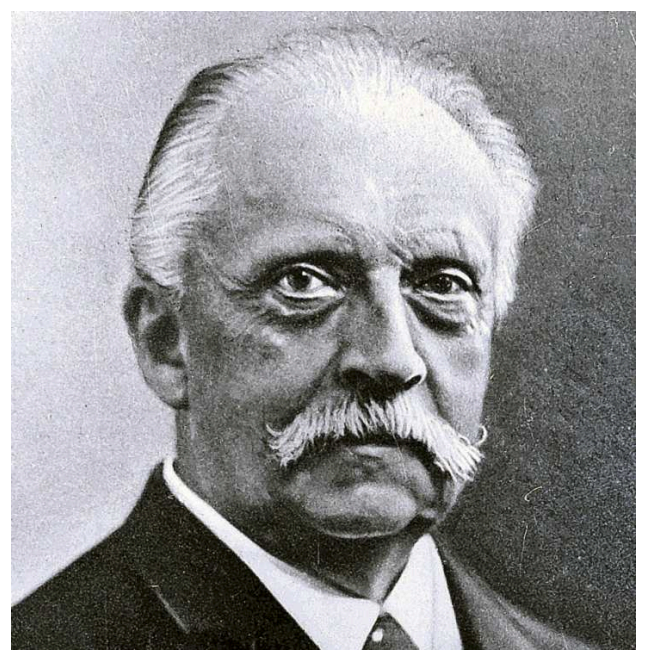

Figure 11: Hermann Ludwig Ferdinand von Helmholtz was born on Aug 31, 1821, and died Sep 8, 1894. He was a German physician and physicist who made significant contributions to diverse areas of modern science. In physics, he is known for his theories on the conservation of energy, work in electrodynamics, chemical thermodynamics, and on a mechanical foundation of thermodynamics. Helmoholtz was a genius polymath.
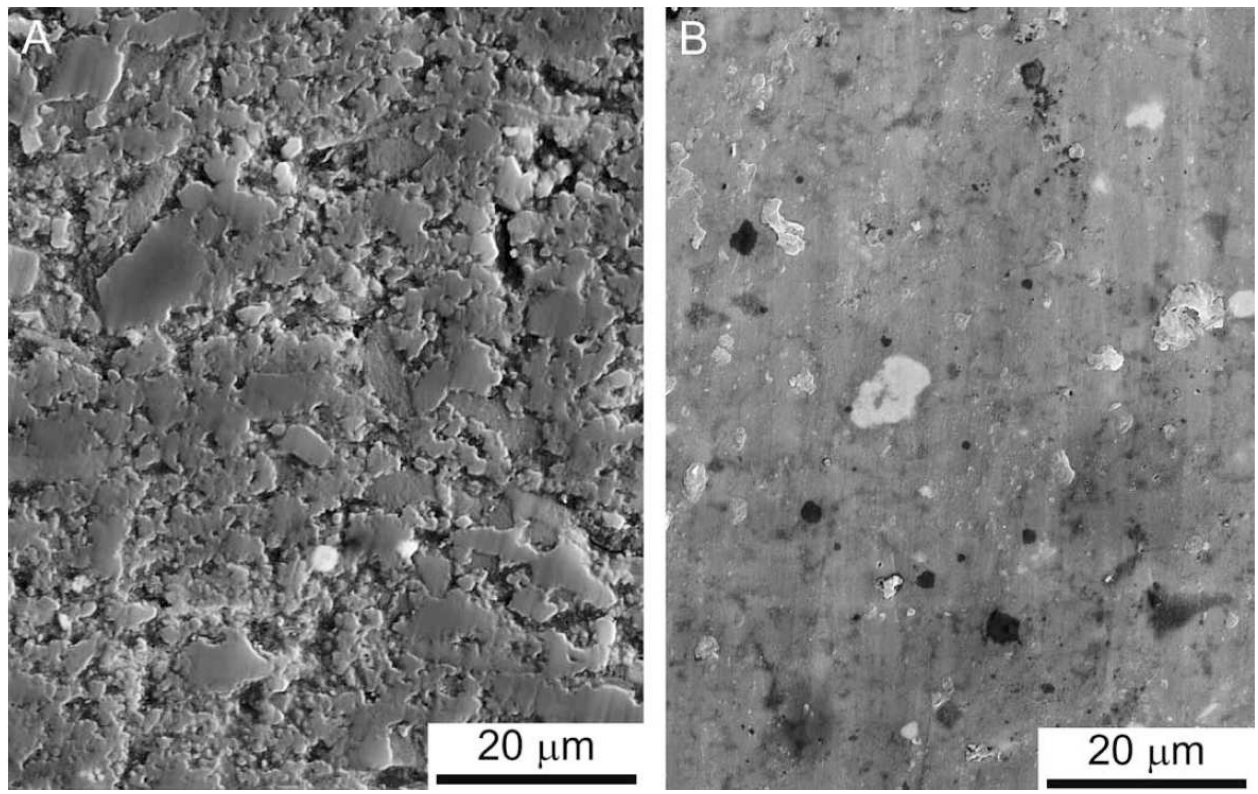

Figure 12: Secondary electron (SE) images at same scale showing the difference in surface topography between A) a mechanically polished surface and B) an Ar-ion beam cut surface. Note that the relief of the mechanically polished surface (A) exceeds the diameter of most shale pores. Blakely \#1, 2,196.4 m. Reproduced from Fig. 3 in Loucks et al. (2009) with permission. 


\section{References}

Adesida, A. G., I. Y. Akkutlu, D. E. Resasco, and C. S. Rai, Kerogen pore size distribution of Barnett Shale using DFT analysis and monte carlo simulations, in paper SPE 147397 presented at the Society of Petroleum Engineers Annual Technical Conference \& Exhibition, Denver, Colorado; October 30 - November 2, 2011.

Athy, L. F., Density, porosity, and compaction of sedimentary rocks, AAPG Bulletin, 14, 1-24, 1930.

Barenblatt, G. I., Scaling phenomena in fluid mechanics, Cambridge University Press, Cambridge, 1994.

Barenblatt, G. I., Scaling, self-similarity and intermediate asymptotics, Cambridge Texts in Applied Mathematics, Cambridge University Press, Cambridge, 1996.

Bingham, E. C., Experimental Investigations upon the Flow of Liquids in Tubes of Very Small Diameter. By J. M. L. POISEUILLE. Translated by Winslow H. Henschel from the Memoirs of the Royal Academy of Sciences of the Institute of France Sci. Math. \& Phys., Vol. IX, Paris, 1846, vol. 1, 1940.

Bird, R. B., W. E. Stewart, and E. N. Lightfoot, Transport phenomena, John Wiley \& Sons, New York, 1960.

Bird, R. B., W. E. Stewart, and E. N. Lightfoot, Transport Phenomena, Wiley International edition, 2nd ed., chap. 14,19,24, Wiley, New York, 2007.

Brown, G. P., A. DiNardo, G. K. Cheng, and T. K. Sherwood, The flow of gases in pipes at low pressures, Journal of Applied Physics, 17(10), 802-813, doi:http://dx.doi.org/10.1063/1.1707647, 1946.

Christopher, R. H., and S. Middleman, Power-Law Flow through a Packed Tube, Industrial \& Engineering Chemistry Fundamentals, 4(4), 422-426, doi:10.1021/i160016a011, 1965.

Clarkson, C., N. Solano, R. Bustin, A. Bustin, G. Chalmers, L. He, Y. Melnichenko, A. Radliński, and T. Blach, Pore structure characterization of north american shale gas reservoirs using usans/sans, gas adsorption, and mercury intrusion, Fuel, 103, 606 - 616, doi:https://doi.org/10.1016/j.fuel.2012.06.119, 2013.

Graham, T., On the law of the diffusion of gases, Journal of Membrane Science, 100(1), 17 - 21, doi: http://dx.doi.org/10.1016/0376-7388(94)00228-Q, 1995.

Hadjiconstantinou, N. G., The limits of Navier-Stokes theory and kinetic extensions for describing small-scale gaseous hydrodynamics, Physics of Fluids, 18(11), doi:http://dx.doi.org/10.1063/1.2393436, 2006.

Helmholtz, H., and G. von Piotrowski, Über Reibung tropfbarer Flüssigkeiten, Wiener Berichte, 40(Abtheilung II), 607-58, 1860 .

Hirschfelder, J. O., C. F. Curtiss, and R. B. Bird, Molecular Theory of Gases and Liquids, John Wiley \& Sons, Inc., New York, 1954.

Islam, A., and T. W. Patzek, Slip in natural gas flow through nanoporous shale reservoirs, Journal of Unconventional Oil and Gas Resources, 7, 49-54, 2014.

Javadpour, F., Nanopores and apparent permeability of gas flow in mudrocks (shales and siltstone), J. Canadian Petroleum Technology, 48(8), 16-21, 2009.

Javadpour, F., D. Fisher, and M. Unsworth, Nanoscale gas flow in shale sediments., J. Canadian Petroleum Technology, 46(10), 55-61, 2007. 
Jin, G., T. W. Patzek, and D. Silin, SPE 90084-MS: Direct Prediction of the Absolute Permeability of Unconsolidated and Consolidated Reservoir Rock, in SPE Annual Technical Conference and Exhibition, SPE, Houston, TX, 2004.

Klinkenberg, L. J., The Permeability of Porous Media to Liquids and Gases, Drilling and Production Practice, API, January 1, 200-213, 1941.

Knudsen, M., Die gesetze der molekularströmung und der inneren reibungsströmung der gase durch röhren, Annalen der Physik, 333(1), 75-130, doi:10.1002/andp.19093330106, 1909.

Knudsen, M., The laws of molecular flow and of inner friction flow of gases through tubes, Journal of Membrane Science, 100(1), 23 - 25, doi:http://dx.doi.org/10.1016/0376-7388(94)00299-E, 1995.

Kundt, A., and E. Warburg, Ueber reibung und wärmeleitung verdünnter gase, Annalen der Physik, 232(10), 177-211, doi:10.1002/andp.18752321002, 1875.

Loucks, R., R. M. Reed, S. C. Ruppel, and U. Hammes, Spectrum of pore types and networks in mudrocks and a descriptive classification for matrix-related mudrock pores, AAPG Bulletin, 96, 1071-1098, 2012.

Loucks, R. G., R. M. Reed, S. C. Ruppel, and D. M. Jarvie, Morphology, Genesis, and Distribution of Nanometer-Scale Pores in Siliceous Mudstones of the Mississippian Barnett Shale, Journal of Sedminetary Research, 79(12), 848 - 861, 2009.

Marder, M., C.-H. Chen, and T. Patzek, Simple models of the hydrofracture process, Phys. Rev. E, 92, 062,408, doi: 10.1103/PhysRevE.92.062408, 2015.

Maxwell, J. C., On the dynamical theory of gases, Philos. Mag., 35, 134, 1868.

Mehmani, A., M. Prodanović, and F. Javadpour, Multiscale, multiphysics network modeling of shale matrix gas flows, Transport in Porous Media, 99(2), 377-390, doi:10.1007/s11242-013-0191-5, 2013.

Nelson, P. H., Pore-throat sizes in sandstones, tight sandstones, and shales, AAPG Bulletin, 93, 329-340, 2009.

Niven, W. D. (Ed.), The scientific papers of James Clerk Maxwell, vol. II, Dover Publications, New York, strangebeautiful.com/other-texts/maxwell-scientificpapers-vol-ii-dover.pdf, 1890.

Øren, P. E., S. Bakke, and O. J. Arntzen, Extending predictive capabilities to network models, Soc. Pet. Eng. J., (3), 324-336, 1998.

Patzek, T., F. Male, and M. Marder, A simple model of gas production from hydrofractured horizontal wells in shales, $A A P G$ Bulletin, 98(12), 2507 - 2529, 2014.

Patzek, T. W., Verification of a complete pore network model of drainage and imbibition, Soc. Pet. Eng. J., 6(2), 144-156, 2001.

Patzek, T. W., and D. B. Silin, Shape factor and hydraulic conductance in noncircular capillaries: I. One-phase creeping flow, J. Colloid and Interface Sci., 296, 295-304, 2001.

Patzek, T. W., F. Male, and M. Marder, Gas production in the Barnett Shale obeys a simple scaling theory, Proceedings of the National Academy of Sciences, 110(49), 19,731 - 19,736, doi:10.1073/pnas.1313380110, 2013. 
Prausnitz, J. M., and P. R. Benson, Effective collision diameters and correlation of some thermodynamic properties of solutions, AIChE Journal, 5(3), 301-303, doi:10.1002/aic.690050310, 1959.

Reif, F., Berkeley Physics Course: Customized Complete Statistical Physics, vol. 5, McGraw-Hill Companies, Inc, New York, 1998.

Ross, D., and R. M. Bustin, Impact of mass balance calculations on adsorption capacities in microporous shale gas reservoirs, Fuel, 86, 2696 - 706, 2007.

Ross, D. J., and R. M. Bustin, The importance of shale composition and pore structure upon gas storage potential of shale gas reservoirs, Marine and Petroleum Geology, 26(6), 916 - 927, doi:https://doi.org/10.1016/j.marpetgeo.2008.06.004, 2009.

Roy, S., R. Raju, H. F. Chuang, B. A. Cruden, and M. Meyyappan, Modeling gas flow through microchannels and nanopores, Journal of Applied Physics, 93(8), 4870-4879, doi:10.1063/1.1559936, 2003.

Silin, D. B., and T. Patzek, Pore space morphology analysis using maximal inscribed spheres, Physica A, 371(2), 336 - 360, 2006.

Sutera, S. P., and R. Skalk, The History of Poiseuille's Law, Ann. Rev. Fluid Mech., 25, 1-19, 1993.

Toledo, P. G., L. E. Scriven, and H. T. Davis, Pore-Space Statistics and Capillary Pressure Curves From Volume-Controlled Porosimetry, SPE Formation Evaluation, March, 46-54, doi:doi:10.2118/19618-PA, 1994.

Tsien, H.-S., Superaerodynamics, Mechanics of Rarefied Gases, Journal of the Aeronautical Sciences, 13(12), 653 - 664, 1946.

Wenski, T. E., T. T. Olson, C. T. Rettner, and A. L. Garcia, Simulations of air slider bearings with realistic gas-surface scattering, ASME. J. Tribol, 120(3), 639-641, doi:doi:10.1115/1.2834599, 1998.

Yu, W., K. Sepehrnoori, and T. W. Patzek, Modeling Gas Adsorption in Marcellus Shale with Langmuir and BET Isotherms, SPE Journal, April, 589-600, 2016.

Yuan, H. H., Pore-Scale Heterogeneity From Mercury Porosimetry Data (includes associated papers 22051 and 22052), SPE Formation Evaluation, June, 233-243, doi:doi:10.2118/19617-PA, 1991.

Yuan, H. H., and B. F. Swanson, Resolving Pore-Space Characteristics by Rate-Controlled Porosimetry, SPE Formation Evaluation, March, 17-24, doi:doi:10.2118/14892-PA, 1989. 


\section{Appendix A. Force Balance in Creeping Flow in Capillaries}

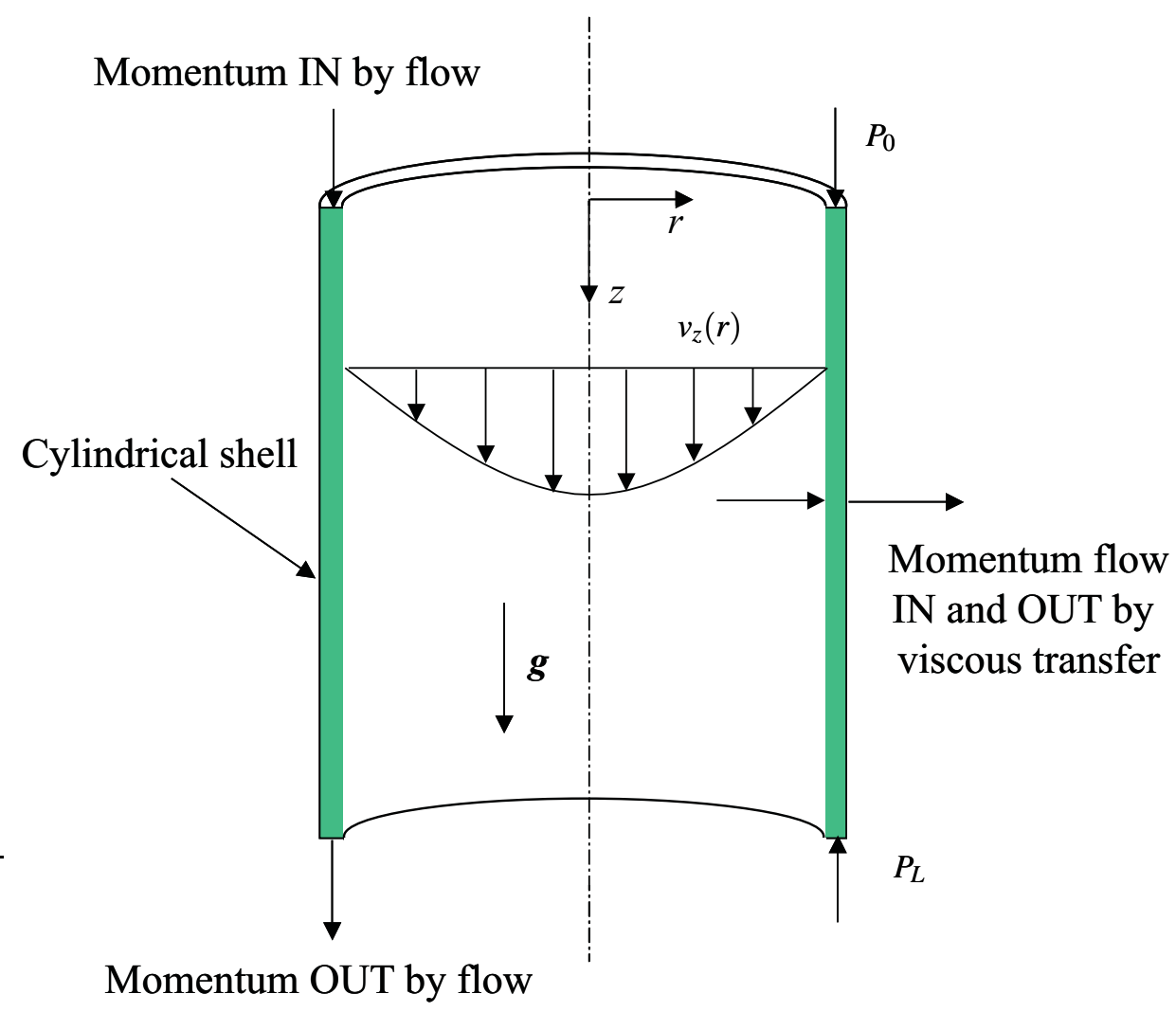

Figure A1: Cylindrical shell of fluid over which forces acting upon fluid are balances to obtain the velocity profile and the Hagen-Poiseuille formula for the volumetric flow rate in a long vertical tube of length $L$ and radius $R$.

We select as our system a cylindrical shell of radius $r$, thickness $\Delta r$ and length $L$, and we list the various forces per unit volume acting on the shell, see Fig. A1. The sum of these forces must be equal to zero in steady state.

The rate of momentum $\mathrm{IN}^{8}$ across the cylindrical surface at $r$ is:

$$
\left.\left(2 \pi r L \tau_{r z}\right)\right|_{r}
$$

The rate of momentum OUT across the cylindrical surface at $r+\Delta r$ is:

$$
\left.\left(2 \pi r L \tau_{r z}\right)\right|_{r+\Delta r}
$$

Rate of momentum IN across the annular surface at $z=0$ :

$$
\left.\left[\left(2 \pi r \Delta r v_{z}\right)\left(\rho v_{z}\right)\right]\right|_{z=0}
$$

Rate of momentum OUT across the annular surface at $z=L$ :

$$
\left.\left[\left(2 \pi r \Delta r v_{z}\right)\left(\rho v_{z}\right)\right]\right|_{z=L}
$$

Gravity force ON the fluid in the cylindrical shell

$$
(2 \pi r \Delta r L)(\rho g)
$$

\footnotetext{
${ }^{8}$ Because of friction, as we move away from the tube axis, each concentric fluid shell loses its momentum to the next one.
} 
Pressure force ON the annular surface at $z=0$ :

$$
2 \pi r \Delta r P_{0}
$$

Rate of force ON the annular surface at $z=L$ :

$$
-2 \pi r \Delta r P_{L}
$$

Note that IN and OUT contributions are positive in the positive direction of the axes.

We add up the contributions to the force balance:

$$
\begin{aligned}
& \text { Accumulation }=0=\mathrm{IN} \text { - OUT } \\
& \left.\left(2 \pi r L \tau_{r z}\right)\right|_{r}-\left.\left(2 \pi r L \tau_{r z}\right)\right|_{r+\Delta r}+\left.\left(2 \pi r \Delta r \rho v_{z}^{2}\right)\right|_{z=0}-\left.\left(2 \pi r \Delta r \rho v_{z}^{2}\right)\right|_{z=L} \\
& +2 \pi r \Delta r L \rho g+2 \pi r \Delta r\left(P_{0}-P_{L}\right)=0
\end{aligned}
$$

In incompressible flow $v_{z}$ is independent of $z$ for a given $r$, and the third and fourth terms cancel each other. We now divide Eq. (A8) by $2 \pi \Delta r L$, substitute $\Phi(z)=P-\rho g h, h=z \sin (\theta)$, where $\theta$ is angle between the direction of flow and horizontal plane ${ }^{9}$, and take the limit as $\Delta r \rightarrow 0$ :

$$
\frac{d}{d r}\left(r \tau_{r z}\right)=\left(\frac{\Phi_{0}-\Phi_{L}}{L}\right) r
$$

Equation (A9) can be integrated:

$$
\tau_{r z}=\left(\frac{\Phi_{0}-\Phi_{L}}{2 L}\right) r+\frac{C_{1}}{r}
$$

The constant $C_{1}=0$ if the momentum flux is to remain finite at $r=0$. Hence the radial distribution of the momentum flux is

$$
\tau_{r z}=\left(\frac{\Phi_{0}-\Phi_{L}}{2 L}\right) r
$$

Now we must invoke a constitutive relation for a Newtonian fluid, linking the shear stress with the fluid velocity:

$$
\tau_{r z}=-\mu \frac{d v_{z}}{d r}
$$

Substitution of this relation into Eq. (A11) gives

$$
\frac{d v_{z}}{d r}=-\left(\frac{\Phi_{0}-\Phi_{L}}{2 \mu L}\right) r
$$

and upon integration:

$$
v_{z}=-\left(\frac{\Phi_{0}-\Phi_{L}}{4 \mu L}\right) r^{2}+C_{2}
$$

Because of the no-slip condition (Assumption 7) we obtain:

$$
v_{z}=\left(\frac{\Phi_{0}-\Phi_{L}}{4 \mu L}\right) R^{2}\left[1-\left(\frac{r}{R}\right)^{2}\right]
$$

Thus, the average fluid flow velocity is

$$
\left\langle v_{z}\right\rangle=\frac{\left(\Phi_{0}-\Phi_{L}\right) R^{2}}{8 \mu L}
$$

and the volumetric flow rate is

$$
Q=\left\langle v_{z}\right\rangle \pi R^{2}=\frac{\left(\Phi_{0}-\Phi_{L}\right) \pi R^{4}}{8 \mu L}
$$

This is the famous Hagen-Poiseuille formula.

\footnotetext{
${ }^{9}$ For vertical flow up, $\theta=\pi / 2$, and $h=z$.
} 


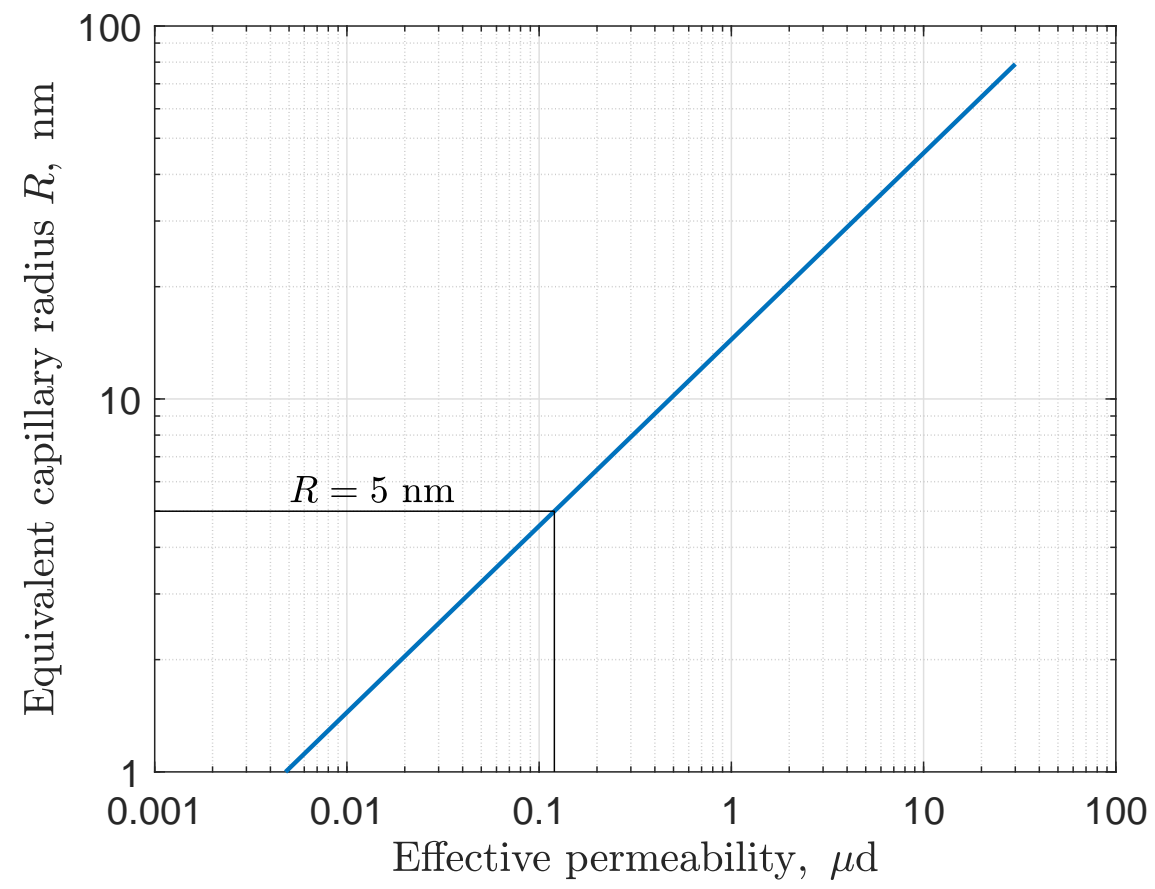

Figure A2: Capillary radius as a function of permeability. For example, $R=5 \mathrm{~nm}$, for $k=0.12 \mu \mathbf{d}$.

Conversion between flow in mudrock and capillaries. One can approximate fluid flow in a rock parallelepiped of length $L$ and cross-sectional area $A$ with the flow in a bundle of equivalent of capillary tubes, whose length $L^{\prime}>L$, because of the tortuosity, $\tau$, of the rock's pore space. In flow of a Newtonian fluid, a good approximation to Blake-Kozeny's equation, Bird et al. (2007), requires, Christopher and Middleman (1965), that

$$
\tau=\frac{L^{\prime}}{L}=\frac{25}{12}
$$

From Eq. (A16) it then follows

$$
\left\langle v_{z}\right\rangle_{\text {capillary }}=\frac{\left(\Phi_{0}-\Phi_{L}\right) R^{2}}{8 \mu L^{\prime}}
$$

The interstitial fluid velocity in a pore, $v_{\text {pore }}$, will be smaller that in the capillary because of the tortuosity of flow paths

$$
v_{\text {pore }}=\frac{\left\langle v_{z}\right\rangle_{\text {capillary }}}{\tau}
$$

In terms of the superficial fluid velocity $u$ and rock porosity $\phi$, we have

$$
u=\frac{Q}{A}=\phi v_{\text {pore }}=\frac{\phi\left(\Phi_{0}-\Phi_{L}\right) R^{2}}{8 \mu L \tau}=\frac{3 \phi R^{2}\left(\Phi_{0}-\Phi_{L}\right)}{50 \mu L}
$$

We identify the equivalent permeability of the bundle's capillaries as

$$
k=\frac{3 \phi R^{2}}{50}
$$

where $k$ is also the rock effective permeability. Then the equivalent capillary radius is

$$
R=\sqrt{\frac{50 k}{3 \phi}}
$$

